\title{
Pharmacokinetics of protocatechuic acid following oral administration of protocatechuic ethyl ester alone and in combination with piperine in rats
}

\author{
Nitin V. Kale, Megha A. Modi, Jatin H. Patel`, Rasesh D. Varia, Falguni D. Modi and Priti D.Vihol* \\ Department of Veterinary Pharmacology and Toxicology, College of Veterinary Science and A.H., Kamdhenu University, Navsari-396450, \\ Gujarat, India \\ * Department of Veterinary Pathology, College of Veterinary Science and A.H., Kamdhenu University, Navsari-396450, Gujarat, India \\ Article Info

\section{Article history} \\ Received 1 November 2021 \\ Revised 16 December 2021 \\ Accepted 17 December 2021 \\ Published Online 30 December 2021

\section{Keywords} \\ Protocatechuic ethyl ester \\ Protocatechuic acid \\ Piperine \\ Pharmacokinetics \\ Rat

\begin{abstract}
The current study was carried out to estimate pharmacokinetics of protocatechuic acid following oral administration of protocatechuic ethyl ester alone and in combination with piperine in rats. Following oral administration of protocatechuic ethyl ester, the mean peak plasma protocatechuic acid concentration of $1.50 \pm 0.08 \mu \mathrm{g} / \mathrm{ml}$ was achieved at $0.25 \mathrm{~h}$. The pharmacokinetic parameters like mean absorption halflife $\left(t_{1 / 2 \alpha}\right)(0.16 \pm 0.07)$, elimination half-life $\left(t_{1 / 2 \beta}\right)(0.43 \pm 0.02 \mathrm{~h})$, apparent volume of distribution (Vdarea) $(102.4 \pm 5.76)$, area under plasma drug concentration-time curve $\left(\mathrm{AUC}_{0-\infty}\right)(0.92 \pm 0.02 \mu \mathrm{g} \mathrm{h} / \mathrm{ml})$, area under first moment curve (AUMC) $(0.56 \pm 0.01 \mu \mathrm{g} \mathrm{h} / 2 / \mathrm{ml})$, total body clearance $\left(\mathrm{Cl}_{\mathrm{B}}\right)(163.7 \pm 3.49$ $1 / \mathrm{h} / \mathrm{kg})$ and mean residence time (MRT) $(0.61 \pm 0.02)$ were observed for protocatechuic acid. Following oral administration of piperine with protocatechuic ethyl ester in rats, plasma concentrations of protocatechuic acid at all time point and pharmacokinetic parameters did not differ significantly in comparison to protocatechuic ethyl ester administered alone.
\end{abstract}

\section{Introduction}

Protocatechuic acid (3, 4-dihydroxybenzoic acid) is a phenolic acid, isolated from the dried flowers of Hibiscus sabdariffa (Tseng et al., 1998) and reported to possess 10 fold higher antioxidant properties than $\alpha$-tocopherol (Li et al., 2011). It is reported to present in routine human diet like brown rice (Oryza sativa L.), onion (Allium cepa L.), plums (Prunus domestica L.), grapes (Vitis vinifera), almonds (Prunus amygdalus), olive oil, white wine, star anise (Illicium verum), rosemary (Rosmarinus officinalis L.), and cinnamon (Cinnamomum aromaticum) (Herrmann and Nagel, 1989; Das and Gezici, 2018; Malik et al., 2020). Literature shows that protocatechuic acid absorption is quite rapid following oral administration but bioavailability and mean residence time is quite low in rat body like other phytochemicals (Chen et al., 2012; Ma et al., 2015; Wang et al., 2016; Modi et al., 2019). So, in order to enhance systemic bioavailability, esterification of protocatechuic acid is one way (Biasutto et al., 2007) and to minimize in vivo metabolism, bioenhancer like piperine can be favorable phytochemical (Singh $e t$ al., 2009; Chauhan et al., 2017; Patel et al., 2019; Patel et al., 2020). Protocatechuic ethyl ester is alkyl ester derivative of protocatechuic acid and it has been widely explored for anticancer activity (Tanaka et al., 2011), antidiabetic activity (Scazzocchio et al., 2011), antiageing activity (Shi et al., 2006), anti-inflammatory activity and analgesic activity (Lende et al., 2011), antiatherosclerotic activity

Corresponding author: Dr. Jatin H. Patel

Assistant Professor, Department of Veterinary Pharmacology and Toxicology, College of Veterinary Science and A.H., Kamdhenu University, Navsari-396450, Gujarat, India

E-mail: jhpatel@kamdhenuuni.edu.in

Tel.: +91-9428489543

Copyright (c) 2021 Ukaaz Publications. All rights reserved.

Email: ukaaz@yahoo.com; Website: www.ukaazpublications.com
(Borate et al., 2011), hepatoprotective activity (Liu et al., 2002) and nephroprotective activity (Lee et al., 2009). Looking to the available literature and with the aim of evaluation of pharmacokinetics of protocatechuic acid following oral administration of protocatechuic ethyl ester in rats with special attention on effect of piperine cotreatment on pharmacokinetic profile of protocatechuic acid, the present study was undertaken.

\section{Materials and Methods}

\subsection{Experimental animals}

The experiment was conducted in 48 Wistar rats (female) weighing between 300 to $400 \mathrm{~g}$. Before commencement of the experiment, rats were subjected to clinical examination to exclude possibility of any disease and kept under constant observation for two weeks. Randomly, the animals were divided into two groups, housed in polypropylene cages with provision of ad libitum standard feed and water. Institutional Animal Ethics Committee, Veterinary College, Navsari, Gujarat approved use of animals for conducting the study with protocol number 062-VCN-VPT-2018.

\subsection{Drugs and chemicals}

Protocatechuic acid, protocatechuic ethyl ester (3, 4-Dihydroxybenzoic acid) and piperine were obtained from Sigma-Aldrich, St. Louis, USA. Caboxy methyl cellulose sodium salt (CMC), Acetonitrile and orthophosphoric acid were purchased from Merck Specialities Private Limited, Mumbai. Normal saline was obtained from local pharmacy located at Navsari, Gujarat.

\subsection{Experimental design for pharmacokinetic study}

Pharmacokinetic of protocatechuic acid was evaluated following oral administration of protocatechuic ethyl ester alone $(150 \mathrm{mg} / \mathrm{kg})$ and 
in combination with piperine $(40 \mathrm{mg} / \mathrm{kg})$ in rats $(\mathrm{n}=48)$. Protocatechuic ethyl ester was dissolved in caboxy methyl cellulose sodium salt solution. Serial collection of blood samples at alternating time points was managed by use of multiple numbers of rats. Blood samples were collected in $\mathrm{K}_{3} \mathrm{EDTA}$ vials, at different time interval i.e., 0.083, $0.250 .5,1,1.5,2,4,6,8$ and $12 \mathrm{~h}$ from retro orbital plexus. Plasma samples were collected by the centrifugation ( $3000 \mathrm{rpm}$ for $10 \mathrm{~min}$ ) and stored at $-20^{\circ} \mathrm{C}$ in cryovials. Samples were processed and analyzed within $24 \mathrm{~h}$ for determination of protocatechuic acid concentration through high performance liquid chromatography (HPLC).

\subsection{HPLC analysis of protocatechuic acid from plasma samples}

Plasma protein was precipitated from plasma samples by adding methanol in plasma (1:1 ratio) in a clean microcentrifuge tube and mixed on a vortex mixer for $1 \mathrm{~min}$. It was followed by centrifugation for $10 \mathrm{~min}$ at $10000 \mathrm{rpm}$ and clean supernatant was collected into inserts of automatic sampler vial, from which $20 \mu$ l of supernatant was injected into HPLC system.

Plasma samples were analyzed to quantify protocatechuic acid using HPLC system by using procedure as described by Chen et al. (2012) and Wang et al. (2016) with minor modifications. HPLC system of Shimadzu (Japan) includes binary gradient delivery pump (model LC 20AP), auto sampler (model SIL 20A) and reverse phase C18 column $(250 \times 4.6 \mathrm{~mm} \mathrm{ID})$ and diode array detector (model SPD M20A). Mobile phase consisted of solvent A (5\% orthophosphoric acid in lab grade water) and solvent B (100\% methanol). Mobile phase was subjected to filtration by $0.2 \mu$ size filter (Axiva $\mathrm{N}_{66}$ ) and degassing by ultra-sonication. Gradient flow of mobile phase was pumped into column at a flow rate of $1.5 \mathrm{ml} / \mathrm{min}$ at ambient temperature as follows $0-5$ min $(10 \%$ solvent $\mathrm{B})$ and $5.01-10 \mathrm{~min}$ (8\% solvent B) and effluent was monitored at $210 \mathrm{~nm}$ wavelength (Patel et al., 2018; Modi et al., 2019).

For validation of HPLC method, initial stock solution of protocatechuic acid was prepared by dissolving $2 \mathrm{mg}$ protocatechuic acid in $1 \mathrm{ml}$ drug free plasma and standards were prepared and analysed to the resultant calibration curve (Figure 1).The calibration curves showed good linearity over the concentration ranges 0.09 to $25 \mu \mathrm{g} / \mathrm{ml}$ with a mean correlation coefficient $\left(\mathrm{R}^{2}\right)$ was 0.99 .
Representative chromatograms of blank plasma of rat, protocatechuic acid standard $(25 \mu \mathrm{g} / \mathrm{ml})$ in plasma, 15 min post oral administration of protocatechuic ethyl ester in rat and $15 \mathrm{~min}$ post oral administration of protocatechuic ethyl ester and in combination with piperine in rat depicted in Figure 2. The precision and accuracy of the assay were assessed using samples at concentration of 25, 6.25, 0.78 and $0.09 \mu \mathrm{g} / \mathrm{ml}$. At all concentrations, the C.V. was less than $7.26 \%$. The lower limit of detection and limits of quantification of the drug was 0.04 and $0.09 \mu \mathrm{g} / \mathrm{ml}$, respectively. Pharmacokinetic parameters were calculated using software PK solution (Version 2.0) which is based on non-compartmental model.

\subsection{Statistical analysis}

All data obtained for pharmacokinetic parameters of protocatechuic acid was presented as mean \pm Standard error (SE). The data for plasma protocatechuic acid concentration suitably tabulated and analyzed by ' $t$ ' test. The levels of significance to observe difference were 0.05 and 0.01 . The $p$ values $<0.05$ and $<0.01$ were considered as statistically significant or highly significant, respectively.

\section{Results}

Protocatechuic acid levels in plasma as a function of time schedule after oral administration of protocatechuic ethyl ester $(150 \mathrm{mg} / \mathrm{kg})$ and its combination with piperine $(40 \mathrm{mg} / \mathrm{kg})$ in rats are presented in Table 1, while semilogarithmic plots of the same have been presented in Figure 3. Pharmacokinetic parameters of protocatechuic acid following oral administration of protocatechuic ethyl ester $(150 \mathrm{mg} /$ $\mathrm{kg}$ ) and its combination with piperine $(40 \mathrm{mg} / \mathrm{kg}$ ) in rats are shown in Table 2.

Following oral administration of protocatechuic ethyl ester alone or in combination with piperine, the mean peak plasma drug concentration of $1.50 \pm 0.08 \mu \mathrm{g} / \mathrm{ml}$ vs $1.67 \pm 0.03 \mu \mathrm{g} / \mathrm{ml}$ was achieved at $0.25 \mathrm{~h}$ which declined and detected as $0.12 \pm 0.01 \mu \mathrm{g} / \mathrm{ml}$ vs $0.12 \pm$ $0.01 \mu \mathrm{g} / \mathrm{ml}$ in plasma at $1.5 \mathrm{~h}$ and beyond then the drug was not detected in plasma. Plasma concentrations of protocatechuic acid at all time point did not differ significantly when protocatechuic ethyl ester administered alone and in combination with piperine.

Table 1: Plasma concentrations $(\mu \mathrm{g} / \mathrm{ml})$ of protocatechuic acid following oral administration of protocatechuic ethyl ester alone $(150 \mathrm{mg} /$ $\mathrm{kg})$ and along with piperine $(40 \mathrm{mg} / \mathrm{kg})$ in rats $(\mathrm{n}=6)$

\begin{tabular}{|c|c|c|}
\hline \multirow[b]{2}{*}{$\begin{array}{l}\text { Time after drug } \\
\text { administration }(h)\end{array}$} & \multicolumn{2}{|c|}{ Plasma concentration of protocatechuic acid } \\
\hline & $\begin{array}{l}\text { Protocatechuic acid } \\
\quad(\text { Mean } \pm \text { SE) }\end{array}$ & $\begin{array}{l}\text { Protocatechuic acid }+ \\
\text { piperine }(\text { Mean } \pm \text { SE) }\end{array}$ \\
\hline 0.08 & $1.16 \pm 0.09$ & $1.22 \pm 0.10$ \\
\hline 0.25 & $1.50 \pm 0.08$ & $1.67 \pm 0.03$ \\
\hline 0.5 & $0.60 \pm 0.02$ & $0.58 \pm 0.04$ \\
\hline 0.75 & $0.43 \pm 0.02$ & $0.42 \pm 0.03$ \\
\hline 1 & $0.27 \pm 0.02$ & $0.25 \pm 0.01$ \\
\hline 1.50 & $0.12 \pm 0.01$ & $0.12 \pm 0.01$ \\
\hline
\end{tabular}

Means within rows did not differ significantly $(p<0.05)$. 
Table 2: Pharmacokinetic parameters of protocatechuic acid following oral administration of protocatechuic ethyl ester alone $(150 \mathrm{mg} / \mathrm{kg})$ and along with piperine $(40 \mathrm{mg} / \mathrm{kg})$ in rats $(\mathrm{n}=6)$.

\begin{tabular}{|c|c|c|c|}
\hline $\begin{array}{c}\text { Pharmacokinetic } \\
\text { parameters }\end{array}$ & Unit & $\begin{array}{c}\text { Protocatechuic } \\
\text { acid }\end{array}$ & $\begin{array}{c}\text { Protocatechuic acid after } \\
\text { co-administration of piperine }\end{array}$ \\
\hline $\mathrm{K}_{\mathrm{a}}$ & $\mathrm{h}^{-1}$ & $8.28 \pm 2.06$ & $8.99 \pm 1.95$ \\
$\beta$ & $\mathrm{h}^{-1}$ & $1.62 \pm 0.08$ & $1.68 \pm 0.08$ \\
$\mathrm{t}_{\mathrm{1} / \mathrm{Ka}}$ & $\mathrm{h}$ & $0.16 \pm 0.07$ & $0.11 \pm 0.03$ \\
$\mathrm{t}_{\mathrm{t} / \mathrm{\beta}}$ & $\mathrm{h}$ & $0.43 \pm 0.02$ & $0.42 \pm 0.02$ \\
$\mathrm{C}_{\max }$ & $\mu \mathrm{g} / \mathrm{ml}$ & $1.50 \pm 0.08$ & $1.54 \pm 0.09$ \\
$\mathrm{~T}_{\max }$ & $\mathrm{h}$ & $0.25 \pm 0.00$ & $0.25 \pm 0.00$ \\
$\mathrm{AUC}_{(0-\infty)}$ & $\mu \mathrm{g} \cdot \mathrm{h} / \mathrm{ml}$ & $0.92 \pm 0.02$ & $0.88 \pm 0.01$ \\
$\mathrm{AUMC}$ & $\mu \mathrm{g} \cdot \mathrm{h}^{2} / \mathrm{ml}$ & $0.56 \pm 0.01$ & $0.53 \pm 0.04$ \\
$\mathrm{Vd}_{(\mathrm{area})}$ & $\mathrm{L} / \mathrm{kg}$ & $102.4 \pm 5.76$ & $102.5 \pm 6.27$ \\
$\mathrm{Cl}_{(\mathrm{B})}$ & $\mathrm{L} / \mathrm{h} / \mathrm{kg}$ & $163.7 \pm 3.49$ & $169.9 \pm 2.61$ \\
$\mathrm{MRT}$ & $\mathrm{h}$ & $0.61 \pm 0.02$ & $0.59 \pm 0.02$ \\
\hline
\end{tabular}

Means within rows did not differ significantly $(p<0.05)$.

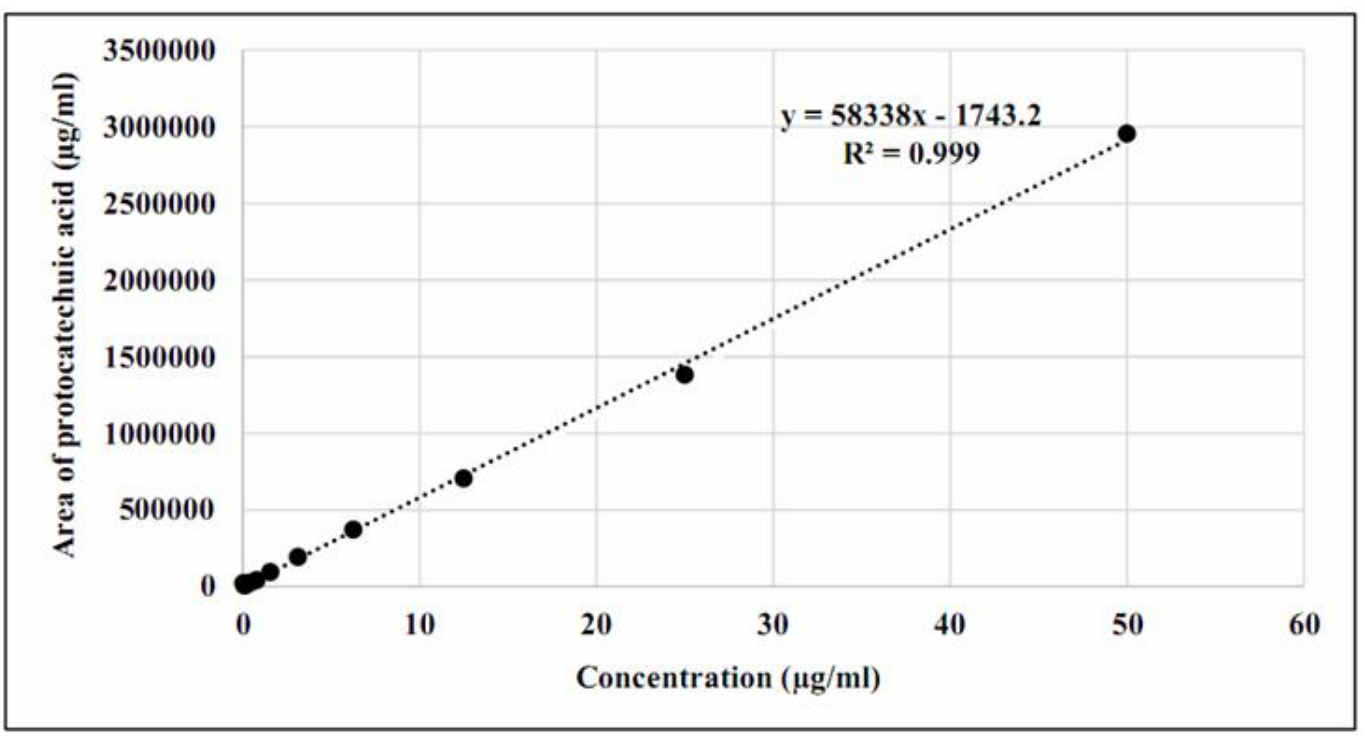

Figure 1: Calibration curve of protocatechuic acid drug-free plasma of rats.
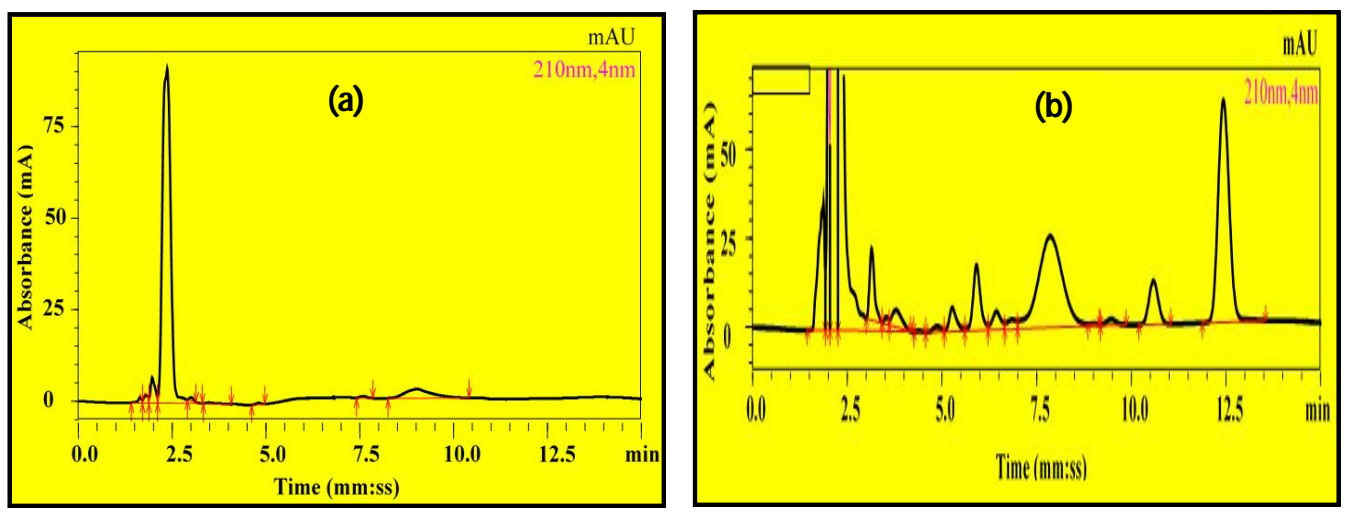

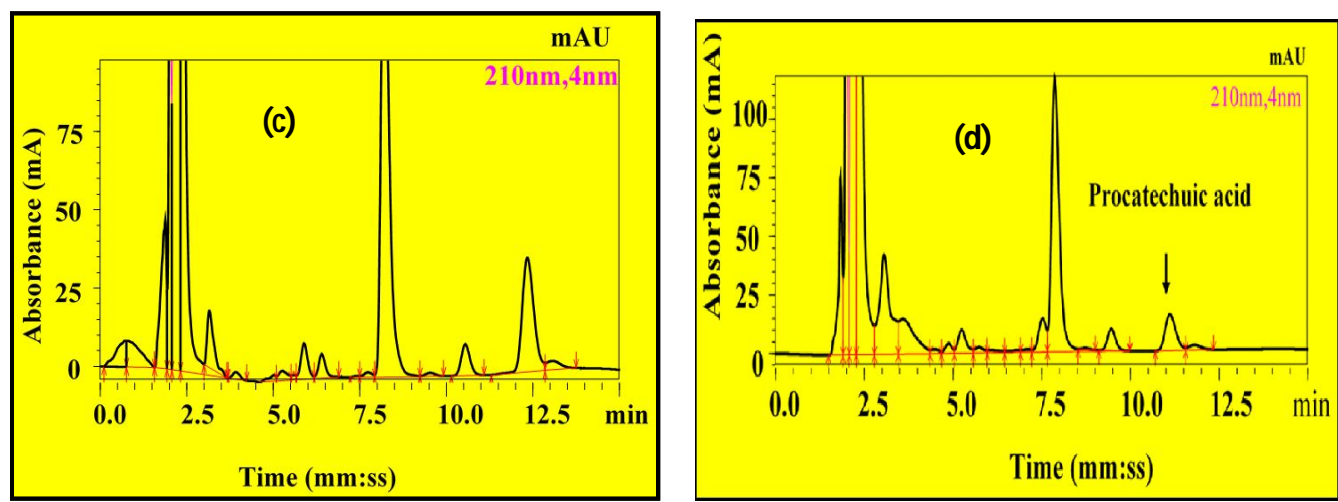

Figure 2: Representative chromatograms of (a) blank plasma of rat, (b) protocatechuic acid standard $(25 \mu \mathrm{g} / \mathrm{ml}$ ) in plasma (c) $15 \mathrm{~min}$ post oral administration of protocatechuic ethyl ester in rat, and (d) 15 min post oral administration of protocatechuic ethyl ester and its combination with piperine in rat.

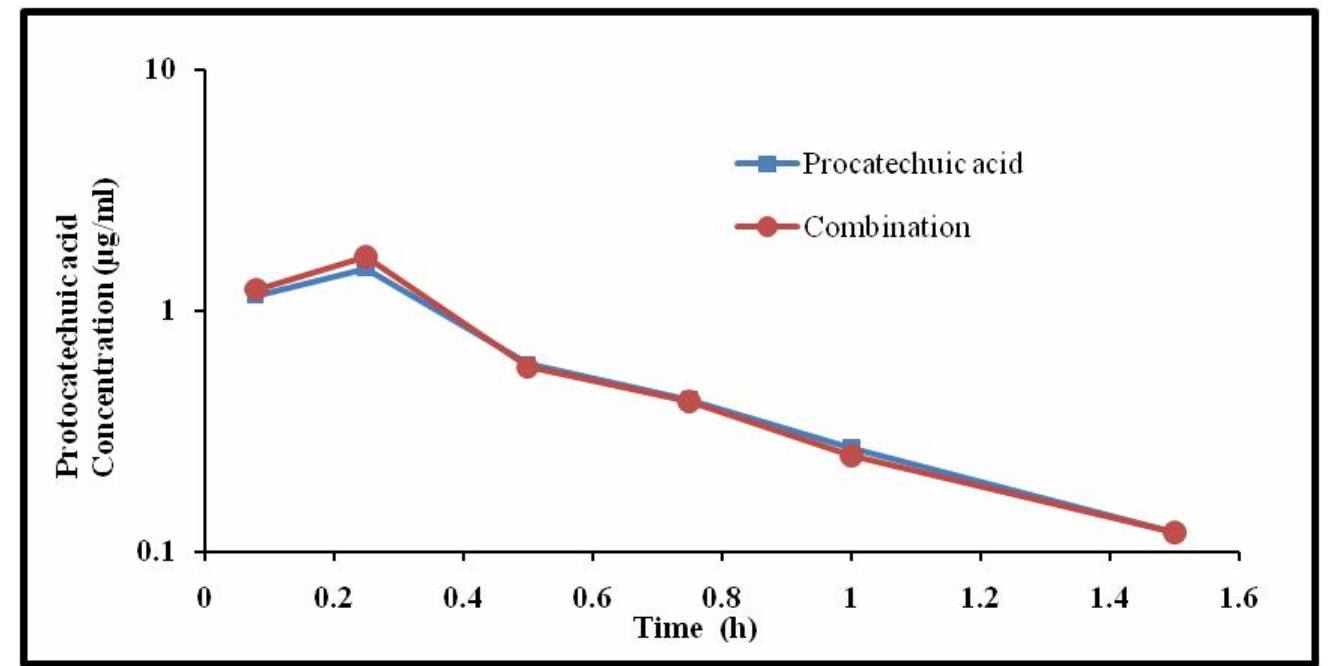

Figure 3: Semi logarithmic plot of comparison of protocatechuic acid concentration in plasma versus time following oral administration of protocatechuic ethyl ester $(150 \mathrm{mg} / \mathrm{kg})$ alone and along with piperine $(40 \mathrm{mg} / \mathrm{kg})$ in rats. Each points represents Mean $\pm \mathrm{SE}$.

\section{Discussion}

Protocatechuic acid peaks were well separated from endogenous substances in the blank plasma as shown in Figure 2, which imply that the bioanalytical method developed herein provide acceptable selectivity without endogenous interferences occurring at the appearance of protocatechuic acid peaks. The calibration curves for protocatechuic acid in plasma were observed to be linear from 0.09 to $25.0 \mu \mathrm{g} / \mathrm{ml}$. A representative equation for the calibration curves is as follows: $y=58338 x-1743.2$. The correlation coefficients $(r 2)$ is 0.99 , indicating an acceptable linearity of method. The intra-day and inter-day accuracy and precision were determined for protocatechuic acid and at the LLOQ $(0.09 \mu \mathrm{g} / \mathrm{ml})$ and four quality control (QC) levels $25,6.25,0.78$, and $0.09 \mu \mathrm{g} / \mathrm{ml}$. The mean precision of the method was determined to be $7.26 \%$, and its mean accuracy was $94.50 \%$. These values were within the acceptable range, indicating that the present method is reproducible, accurate, and precise. Notably, present method with a simple deproteinization procedure achieved an equivalent LLOQ $(0.09 \mu \mathrm{g} / \mathrm{ml})$ in a previous studies involving liquid-liquid extraction (Chen et al., 2012; Wang et al., 2016).

To the best of our knowledge, we carried out the pharmacokinetic study of protocatechuic acid following oral administration of protocatechuic ethyl ester $(150 \mathrm{mg} / \mathrm{kg})$ along with piperine $(40 \mathrm{mg} /$ $\mathrm{kg}$ ) in rats first time. The mean peak plasma drug concentration $\left(\mathrm{C}_{\max }\right)$ of $1.50 \pm 0.08 \mu \mathrm{g} / \mathrm{ml}$ was achieved at $0.25 \mathrm{~h}$. In accordance to present study, similar peak plasma concentration of protocatechuic acid $(4.8 \mu \mathrm{g} / \mathrm{ml}$ at $0.18 \mathrm{~h})$ was observed following oral administration $(20 \mathrm{mg} / \mathrm{kg}$ ) of protocatechuic acid aldehyde in rats (Wang et al., 2016). In addition, Ma et al. (2015), Guo et al. (2008) and Zhao et al. (2011) observed $\mathrm{C}_{\max }$ and $\mathrm{T}_{\text {max }}$ as $0.03 \mu \mathrm{g} / \mathrm{ml}$ at $0.6 \mathrm{~h}, 2.90 \pm 1.73 \mu \mathrm{g} /$ $\mathrm{ml}$ at $0.38 \mathrm{~h}$ and $2.6 \pm 0.3 \mu \mathrm{g} / \mathrm{ml}$ at $0.8 \mathrm{~h}$, following oral administration of Polygonum capitatum extract $(120 \mathrm{mg} / \mathrm{kg})$, following intravenous administration of guanxinning lyophilizer $(800 \mathrm{mg} / \mathrm{kg})$ and following intravenous administration of Danshen injection $(10 \mathrm{ml} / \mathrm{kg})$ in rats, 
respectively. Variation in plasma concentration of protocatechuic acid may be due to variation in dose of drug administration, formulation and other ingredients of plant extracts. In present study, following oral administration of piperine with protocatechuic ethyl esterin rats, plasma concentration of protocatechuic acid did not differ significantly $(p<0.05)$.

The elimination half-life $\left(t_{1 / 2 \beta}\right)$ of protocatechuic acid following oral administration of protocatechuic ethyl ester in the present study was $0.43 \pm 0.02 \mathrm{~h}$. In accordance to present study, Chen et al. (2012) observed terminal half-life $\left(\mathrm{t}_{1 / 2}\right)$ of $0.04 \mathrm{~h}$ following oral administration $(50 \mathrm{mg} / \mathrm{kg})$ in mice; Ma et al. (2015) observed elimination half-time of $0.08 \mathrm{~h}$ for protocatechuic acid following oral administration of Polygonum capitatum extract $(120 \mathrm{mg} / \mathrm{kg})$ in rats and Guo et al. (2008) observed elimination half-life of $0.38 \mathrm{~h}$ for protocatechuic acid following intravenous administration of guanxinning lyophilizer $(800 \mathrm{mg} / \mathrm{kg})$. Mean apparent volume of distribution $\left(\mathrm{Vd}_{\text {area }}\right)$ of protocatechuic acid following oral administration of protocatechuic ethyl ester was $102.4 \pm 5.761 / \mathrm{kg}$ in rats. In accordance to present study, higher volume distribution (Vd) i.e., $128.8 \mathrm{l} / \mathrm{kg}$ and $2.5 \mathrm{l} / \mathrm{Kg}$ were observed for protocatechuic acid following oral administration of Polygonum capitatum extract (120 mg/kg) in rats (Ma et al., 2015) and following intravenous administration of danshen injection (10 $\mathrm{ml} / \mathrm{kg}$ ) (Zhao et al., 2011). However, lower values for volume of distribution $\left(\mathrm{V}_{\mathrm{d}}\right)$, i.e., $0.03 \mathrm{l} / \mathrm{kg}$ was observed following oral administration of protocatechuic acid $(50 \mathrm{mg} / \mathrm{kg})$ in mice (Chen et al., 2012).

The total body clearance of protocatechuic acid was observed to be $163.7 \pm 3.49 \mathrm{1} / \mathrm{h} / \mathrm{kg}$ following oral administration $(150 \mathrm{mg} / \mathrm{kg})$ of protocatechuic ethyl ester in rats. In accordance to present study, high total body clearance of protocatechuic acid, i.e., $67.68 \mathrm{1} / \mathrm{h} / \mathrm{kg}$, $267.6 \mathrm{l} / \mathrm{h} / \mathrm{kg}$ and $608.33 \mathrm{l} / \mathrm{h} / \mathrm{kg}$ were observed following oral administration of Polygonum capitatum extract $(120 \mathrm{mg} / \mathrm{kg})$ in rats (Ma et al., 2015), following by oral administration $(50 \mathrm{mg} / \mathrm{kg}$ ) (Chen et al., 2012) and following intravenous administration of danshen injection in rats (Zhao et al., 2011). The MRT values calculated following oral administration of protocatechuic acid in present study was $0.61 \pm 0.02 \mathrm{~h}$. Similarly, Wang et al. (2016) observed MRT of $1.32 \pm 0.79 \mathrm{~h}$ and $0.81 \pm 0.17 \mathrm{~h}$ for protocatechuic acid following oral $(20 \mathrm{mg} / \mathrm{kg})$ and intravenous administration $(1 \mathrm{mg} /$ $\mathrm{kg}$ ) of protocatechuic aldehyde (PAL). In addition to this, Chang et al., (2010) and Zhao et al., (2011) also observed similar MRT value of $0.358 \mathrm{~h}$ and $0.686 \mathrm{~h}$ for protocatechuic acid following intravenous administration of danshen injection in rats.

Pharmacokinetic analysis of protocatechuic acid indicates faster absorption and clearance of drug from the body following oral administration of protocatechuic ethyl ester in rat. This result is supported by observations of Xu et al. (2007), i.e., protocatechuic aldehyde (PAL) metabolic products (free and conjugate forms) was detected at $5 \mathrm{~min}$ in the plasma and reached the peak level at $15 \mathrm{~min}$ after protocatechuic aldehyde administration and Ma et al. (2015), i.e., protocatechuic acid were excreted more than $80 \%$ in the first $4 \mathrm{~h}$ after oral administration of Polygonum capitatum extract. All pharmacokinetic parameter of protocatechuic acid did not differ significantly following co-administration of piperine with protocatechuic ethyl ester in comparison to administration of protocatechuic acid alone in rats.

\section{Conclusion}

In conclusion, following oral administration of protocatechuic ethyl ester alone and along with piperine in rats, effective concentrations were maintained up to $1 \mathrm{~h}$ post drug administration. In rats, protocatechuic acid remains for a shorter time after oral administration in rats due to rapid clearance from the body. Oral administration of piperine with protocatechuic ethyl ester did not affect overall pharmacokinetic profile of protocatechuic acid.

\section{Acknowledgements}

The authors are highly thankful to College of Veterinary Science and A. H., Navsari, Gujarat, India for providing funds, and animal facilities to undertake the research work.

\section{Conflict of interest}

The authors declare no conflicts of interest relevant to this article.

\section{References}

Biasutto, L.; Marotta, E.; De Marchi, U.; Zoratti, M. and Paradisi, C. (2007).Esterbased precursors to increase the bioavailability of quercetin. J. Med. Chem., 50(2):241-253.

Borate, A.R.; Suralkar, A.A.; Birje, S.S.; Malusare, P.V. and Bangale, P.A. (2011). Antihyperlipidemic effect of protocatechuic acid in fructose induced hyperlipidemia in rats. Int. J. Pharma. Bio. Sci., 2(4):456-460.

Chang, B.B.; Zhang, L.; Cao, W.W.; Cao, Y.; Yang, W.L.; Wang, Y.; Chen Y.C. and Liu, X.Q. (2010). Pharmacokinetic interactions induced by content variation of major water-soluble components of Danshen preparation in rats. Acta. Pharmacol. Sin., 31(5):638.

ChauhanV.B.; ModiC.M.; Patel U.D.; Patel H.B.;KalariaV.A.; FefarD.T.; BhadarkaD.H.;SolankiS.L. and Ahmed S.R. (2017).Safety profile of marbofloxacin following repeated intramuscular administration alone and piperine pretreated rats. Ann. Phytomed., 6(2):88-92.

Chen, W.; Wang, D.; Wang, L.; Bei, D.; Wang, J.; See, W.A.; Mallery, S.R.; Stoner, G.D.and Liu, Z. (2012). Pharmacokinetics of protocatechuic acid in mouse and its quantification in human plasma using LC-tandem mass spectrometry. J. Chromatogr. BBiomed. Appl., 908:39-44.

Das Kuntal and Gezici Sevgi (2018).Plant secondary metabolites, their separation, identification and role in human disease prevention. Ann. Phytomed., 7(2): 13-24.

Guo, X.; Chen, X.; Li, L.; Shen, Z.; Wang, X.; Zheng, P.; Duan F.; Ma. Y. and Bi, K. (2008). LC-MS determination and pharmacokinetic study of six phenolic components in rat plasma after taking traditional Chinese medicinal-preparation: Guanxinning lyophilized powder for injection. J. Chromatogr. BBiomed. Appl., 873(1):51-58.

Herrmann K. and Nagel C. W. (1989). Occurrence and content of hydroxycinnamic and hydroxybenzoic acid compounds in foods. Crit. Rev. Food. Sci. Nutr., 28(4):315-347.

Lee, J.H.; Lee, H.J.; Lee, H.J.; Choi; W.C.; Yoon, S.W.; Ko, S.G.; Ahn K.S.; Choi S.H.; Ahn K.S; Lieske J.C. and Kim, S.H. (2009). Rhusverniciflua Stokes prevents cisplatin-induced cytotoxicity and reactive oxygen species productionin MDCK-I renal cells and intact mice. Phytomedicine, 16(2-3):188-197.

Lende, A.B.; Kshirsagar, A.D.; Deshpande, A.D.; Muley, M.M.; Patil, R.R.; Bafna, P.A. and Naik, S.R. (2011). Anti-inflammatory and analgesic activity of protocatechuic acid in rats and mice. Inflammopharmacology, 19(5): 255 .

Li, X.; Wang, X.; Chen, D. and Chen, S. (2011).Antioxidant activity and mechanism of protocatechuic acid in vitro. Funct. Food Health Dis., 1(7):232-244. 
Liu, C.L.; Wang, J.M.; Chu, C.Y.; Cheng, M.T. and Tseng, T.H. (2002). In vivo protective effect of protocatechuic acid on tert-butyl hydroperoxide -induced rat hepatotoxicity. Food Chem. Toxicol., 40(5):635-641.

Ma, F.; Gong, X.; Zhou, X.; Zhao, Y. and Li, M. (2015). An UHPLC-MS/MS method for simultaneous quantification of gallic acid and protocatechuic acid in rat plasma after oral administration of Polygonum capitatum extract and its application to pharmacokinetics. J. Ethnopharmacol, 162:377-383.

Malik T.; Madan V. K. and Ram Prakash( 2020). Herbs that heal: Floristic boon to the natural healthcare system. Ann. Phytomed., 9(2):6-14.

Modi Falguni, D., Bhavsar, S. K., Patel, J. H.; Varia, R.D.; Modi, L.C.; Modi, Megha A. and Kale, N. (2019). Pharmacokinetic profile of rutin after intramuscular administrationin rats favours its in vivo antiinflammatory activity in carrageenan induced rodent model of inflammation. Ann. Phytomed., 8(1):185-192.

Modi, M.A.; Kale, N.V.; Patel, J.H.; Varia, R.D.; Modi, F.D. and Vihol, P.D. (2019). Pharmacokinetics of ferulic acid following oral administration ethyl ferulate alone and in combination with piperinein rats. Ann. Phytomed., 8(2):194-198.

Patel, J.H.; Vihol,P.D.; Sadariya, K.A.; Patel, U.D., Varia, R.D.; Bhavsar, S.K.; Thaker, A.M. and Raval, J.K. (2019).Pretreatment with trikatu augments pharmacokinetic profile and bioavailability of orally administered levofloxacin in goat. Ann. Phytomed., 8(1):172-177.

Patel Harshad, B.; Patel Urvesh, D.; Modi Chirag, M.; Fefar Dhaval, T. and Bhadaniya Amit R. (2020). Effect of piperine and quercetin pretreatment on safety profile of marbofloxacin after repeated oral administration in broiler chickens. Ann. Phytomed., 9(2):283-292. http:// dx.doi.org/10.21276/ap.2020.9.2.28.

Patel Harshad, B.; Patel Urvesh, D.; Modi Chirag, M.; Ahmed Shaul and Solank Shivani, L. (2018). Pharmacokinetic profiles of marbofloxacin following single and repeated oral administration in broiler chickens. Ann. Phytomed., 7(2):174-179.
Scazzocchio, B.; Varì, R.; Filesi, C.; D'Archivio, M.; Santangelo, C.; Giovannini, C. Iacovelli, A.; Silecchia, G; Volti G.L.; Galvano F.; and Masella, R. (2011). Cyanidin-3-O- $\beta$-glucoside and protocatechuic acid exert insulinlike effects by upregulating PPAR $\gamma$ activity in human omental adipocytes. Diabetes, 60(9):2234-2244.

Shi, G.F.; An, L.J.; Jiang, B.; Guan, S.; and Bao, Y.M. (2006). Alpinia protocatechuic acid protects against oxidative damage in vitro and reduces oxidative stress in vivo. Neurosci. Lett, 403(3):206-210.

Singh, R.; Sarita Devi; Patel, J.H.; Patel, U.D.; Bhavsar and S.K.; Thaker, A.M. (2009). Indian herbal bioenhancers: A review. Pharmacogn. Rev., 3(5):80-82.

Tanaka, T.; Tanaka, T. and Tanaka, M. (2011). Potential cancer chemopreventive activity of protocatechuic acid. J. Exp. Clin. Med., 3(1):27-33.

Tseng, T.H.; Hsu, J.D.; Lo, M.H.; Chu, C.Y.; Chou, F.P.; Huang, C.L. and Wang, C.J. (1998). Inhibitory effect of Hibiscus protocatechuic acid on tumor promotion in mouse skin. Cancer Lett, 126(2):199-207.

Wang, X.; Yan, K.; Ma, X.; Li, W.; Chu, Y.;Guo, J.; Li, S.; Zhou, S.; Zhu, Y. and Liu, C. (2016). Simultaneous determination and pharmacokinetic study of protocatechuic aldehyde and its major active metabolite protocatechuic acid in rat plasma by liquid chromatography-Tandem mass spectrometry. J. Chromatogr. Sci., 54(5):697-705.

Xu,M.; Zhang,Z.; Fu, G.; Sun, S.; Sun, J.; Yang, M.; Liu, A.; Han, J. and Guo, D.(2007). Liquid chromatography-tandem mass spectrometry analysis of protocatechuic aldehyde and its phase I and II metabolites in rat. J. Chromatogr. BBiomed. Appl., 856(1-2):100-107.

Zhao, D.; Han, D.E.; Li, N.; Lu, Y.; Li, T.T.; Yang, S.Y.; He, J.K. and Chen, X.J. (2011). Simultaneous determination of six phenolic constituents of danshen injection in rat plasma by liquid chromatography electrospray ionization mass spectrometry and its application to a Pharmacokinetic Study. Eur. J. Mass Spectrom., 17(4):395-403. 